\title{
Entre Condições e Hipóteses: Empirismo e Cultura
}

\author{
João Carlos CATTELAN \\ Universidade Estadual do Oeste do Paraná - \\ Marechal Cândido Rondon \\ Luciane Thomé SCHRÖDER \\ Faculdade de Ciências Sociais e Aplicadas de Cascavel
}

\begin{abstract}
Resumo: A conjunção subordinativa se é tratada pela gramática tradicional como um conetivo que cria uma relação condicional ou hipotética entre as orações. Um fato seria uma condição ou hipótese que deveria realizar-se para que o outro pudesse realizar-se. Considerada sob a perspectiva da Lingüística Textual, essa conjunção é vista como um conetivo lógico-semântico, já que, diferentemente dos operadores discursivo-argumentativos, que tomam como eixo de reflexão a interação dos protagonistas do discurso, as suas relações se dariam entre as orações, dentro de uma visada lingüística. Este texto tece reflexões sobre estas formas de concepção e pleiteia a existência de, pelo menos, dois $\mathbf{s e}(\mathrm{s}$ ), ambos de caráter discursivo (um mais evidentemente que outro): o primeiro teria como base o sistema de referência do mundo objetivo; o segundo teria como pano de fundo o lastro cultural de um grupo, o que se pode provar pelo fato de apenas o último suportar uma contra-enunciação irônica.

Palavras-chave: Discurso, Conjunção, Condição, Cultura.
\end{abstract}

Abstract: The subordinate conjunction if is treated by the traditional
grammar as a connective that creates a conditional or hypothetical
relation between the phrases. A fact would be a condition or a
hypothesis that would have to be become fulfilled so that the other
could be carried through. Considered under the perspective of Textual
Linguistics, this conjunction is considered as a logical-semantic
connective, since, differently of the discursive-argumentative operators,
that they would take as reflection axe the interaction of discourse
protagonists, its relations would occur between the joints inside of a 
properly linguistic point of view. This text makes some reflections on these forms of conception and to plead the existence of, at least, two if $(\mathrm{s})$, both of discursive character (one more evidently that another one): the first one would have as base the system of reference of the objective world; the second one would have as background the cultural ballast of a social group, what it can be proved by the fact of only the last one to support an ironic against-enunciation.

Key words: Discourse, Conjunction, Condition, Culture.

Resumen: La conjunción subordinante si es tratada por la gramática tradicional como conectador que crea una relación condicional o hipotética entre las oraciones. Un hecho sería una condición o una hipótesis que tendría que realizarse para que el otro se pudiera ocurrir. Considerada bajo la perspectiva de la Lingüística literal, esta conjunción es considerada como un conectador lógico-semántico, puesto que, distintamente de los operadores discursivo-argumentativos, que tomarían como base de la reflexión la interacción ocurrida de los protagonistas del discurso, suyas relaciones si darían entre oraciones, dentro de un punto de vista propiamente lingüístico. Este texto hace algunas reflexiones sobre estas formas de concepción y aboga la existencia de, por lo menos, dos si(s), ambos de carácter discursivo (uno más evidentemente que otro): lo primer tendría como base el sistema de referencia del mundo objetivo; lo segundo tendría como paño de fundo el lastre cultural de un grupo, lo que si puede demostrar por el hecho de solamente lo último apoyar una contra-articulación irónica.

Palabras-clave: Discurso, Conjunción, Condición, Cultura.

\section{Introdução}

O mirante em que o estudioso se instala para observar o objeto que pretende elucidar the permite ver, como qualquer mirante, por mais que o olhar rodopie de forma completa sobre si mesmo, apenas alguns aspectos do todo fenomenológico que tem diante de si. Escolha o fundo exotópico que pareça mais adequado, ainda assim o objeto não se revelará integralmente. Assuma um ponto de vista teórico que sugira um pano de fundo mais lúcido e mais bem embasado, 
mesmo assim será um recorte o que vê e não o objeto na sua inteireza. Lição dura de aprender: às vezes, a especialidade num foco de olhar produz tão farto volume de reflexão que parece não existirem outros ou se pensa que eles devem estar enganados.

Este estudo se constitui pela mescla de três pontos de vista distintos, sem que se considere que entre eles haja uma relação de hierarquia ou que se deva criticar dois deles para, no fim, assumir um como mais consistente. Valendo-nos das suas limitações, naturais (isto não é uma crítica), e dos seus acertos (isto não é um juízo de valor), tentamos carrear ensinamentos que podem ajudar a elucidar o objeto em estudo e demonstrar a tese que acreditamos poder defender. Estes três pontos de vista são os da Gramática Tradicional normativa, da Lingüística Textual anglo-germânica e da Análise do Discurso, pelo menos de um de seus matizes de reflexão.

Objetivamos buscar, por meio de ensinamentos provindos de cada um deles, refletir sobre um conetivo em especial, o se (e seus correlatos), dado como criador de relações hipotéticas ou de condicionalidade entre os segmentos que aproxima. Pretendemos, usando estas três teorias (um pecado epistemológico, em dependendo de quem o observe), mostrar que este conetivo sempre está ligado a condições discursivas de produção que não podem ser tratadas de forma genérica, já que ele, às vezes, até se aproxima do sistema de referência que toma o mundo objetivo como filtro de leitura, mas, muitas vezes (quem sabe, na maioria dos casos), tem um viés discursivoargumentativo, pois se ancora na mentalidade cultural de um grupo.

\section{Se, Então: O Ponto de Vista Gramatical}

É comum que se afirme que a Gramática Tradicional tem como eixos básicos de reflexão a lógica e a filosofia: ela teria uma natureza lógico-filosófica. Lógica, porque procura detectar princípios gerais de comportamento que perpassam fenômenos lingüísticos, atitude que se pode perceber no tratamento dado ao se, que seria um conetivo que sempre estabelece uma relação de hipótese ou de condição entre os enunciados. E filosófica, por decorrência: ela buscaria detectar a essência dos fenômenos: a sua natureza ontológica. Uma vez estabelecido o comportamento lógico, com o acréscimo de que 
equivaleria a uma das leis da racionalidade humana, a uma das leis do pensamento, o mundo passa a ser concebido pela hipótese, e não o inverso. Neste sentido, os estudos gramaticais agem por abstração, voltando-se para um plano puramente lingüístico, imanente e estrutural (não há uma crítica nisto, nem estamos sendo pejorativo): nada a criticar: eis a eleição de um ponto de vista. Pensamos ser produtivo ouvir o que os gramáticos têm a dizer sobre o conetivo condicional.

Para André (1978, p. 232), as conjunções "condicionais ligam duas orações, sendo que a segunda expressa uma hipótese ou condição" em relação à oração principal componente do período ou recorte do texto. O gramático dá como exemplos para tais tipos de conjunções os períodos arrolados a seguir:

1) $[\text { Se o pai deixasse, }]_{1}$ [Manuel namoraria Isabel. $]_{2}$

2) $[\mathrm{O} \text { passeio acontecerá, }]_{3}$ [se não sobrevier um temporal. $]_{4}{ }^{*}$

3) [Não viajarás, $]_{5}$ [se não obtiveres visto no passaporte. $]_{6} \mathrm{e}$

4) $[\text { Se o encontrares, }]_{7}$ [dá-lhe o meu recado. $]_{8}$

Para o autor, as orações 4 e 6 expressam as condições que devem ser atendidas para que os eventos expressos em 3 e 5 possam se realizar. No caso de 1 e 7 , ele considera as orações como hipóteses que, atendidas, permitem as ocorrências solicitadas em 2 e 8 .

De acordo com Cunha e Cintra (1999, p. 572), as conjunções "condicionais (iniciam uma oração subordinada em que se indica uma hipótese ou uma condição necessária para que seja realizado ou não o fato principal)". Os autores apresentam como exemplos para o fenômeno estudado os mencionados a seguir:

5) $[\text { Se um entrasse, }]_{1}$ [também os outros poderiam tentar. $]_{2}$

6) [A visita ficou para a tarde, $]_{3}$ [se você não vai à noite. $]_{4} \mathrm{e}$

7) [Contar-lhe-ei o caso, $]_{5}$ [se você guardar segredo. $]_{6}$

\footnotetext{
* Nos exemplos dados pelos gramáticos, não é apenas o se que aparece como conjunção condicional. Nos casos em que os exemplos dados por eles se valem de outros conetivos desta natureza, nós os estamos substituindo pelo se, mas não queremos dizer com isso que o que afirmamos neste estudo valha só para ele e não diga respeito aos demais.
} 
Para os autores, as orações 1 e 4 expressariam uma relação semântica de hipótese em relação aos conteúdos expressos em 2 e 3 e a oração 6 constituiria um efeito de sentido de condição em relação ao conteúdo de 5.

Para Cegalla (1981, p. 160), as conjunções condicionais "iniciam uma oração que indica condição ou hipótese" e apresenta como dados comprobatórios os relacionados a seguir:

8) [Ficaremos sentidos, $]_{1}$ [se você não vier. $]_{2}$

9) [Comprarei o quadro, $]_{3}$ [se não for caro. $]_{4}$

10) [Não sairás daqui, $]_{5}$ [se não me confessares tudo. $]_{6} \mathrm{e}$

11) $[\text { Ele dormiria na areia, }]_{7}[\text { se os mosquitos deixassem. }]_{8}$

Para o autor, a oração 2 estabelece uma relação de hipótese com relação à de número 1 e as orações 4,6 e 8 expressam as condições que devem ser atendidas, para que os fatos expressos em 3 , 5 e 7 possam se realizar.

Bechara (2003, p. 327), por fim, afirma que as conjunções são "condicionais (e hipotéticas): quando indicam oração que em geral exprime: a) uma condição necessária para que se realize ou se deixe de realizar o que se declara na oração principal; b) um fato - real ou suposto - em contradição com o que se exprime na principal". Os exemplos apresentados são:

12) $[\text { Se os homens não tivessem alguma coisa de loucos, }]_{1}[$ seriam incapazes de heroísmo. $]_{2} \mathrm{e}$

13) [Se as viagens simplesmente instruíssem os homens, $]_{3}$ [os marinheiros seriam os mais instruídos. $]_{4}$

Para o gramático, entre a oração 1 e a 2 estabelece-se uma relação hipotética, relação semântica exercida basicamente pela oração 1 em relação à 2 . Já entre 3 e 4, a relação de sentido é de condição, pois, embora viajem muito, os marinheiros não são necessariamente bem instruídos, pelo menos de certo ponto de vista do que seja instrução.

Não é preciso ir além; os demais gramáticos trabalham na mesma direção. Eles são recorrentes na afirmação de que os 
conetivos como o se introduzem orações que criam uma relação semântica de condição ou de hipótese em relação à afirmação da oração principal. As idéias de condição ou hipótese são reiteradas e acreditamos que podem ser dadas como estabelecidas doravante. Julgamos, porém, que duas ressalvas devam ser feitas.

A primeira se refere ao fato de que os estudiosos analisados não explicitam que tipo de distinção estão fazendo quando afirmam que os conetivos condicionais criam uma relação de hipótese ou condição: e as duas, obviamente, não são a mesma coisa. Pensamos que apenas a definição de Bechara (2003) permite alguma luz sobre como os dois conceitos se distinguem entre si, pois o autor fala sobre "uma condição necessária" para a realização do fato expresso na principal, no caso das condicionais, e "um fato - real ou suposto", no caso das hipotéticas. Tais afirmações permitem concluir que os conetivos condicionais expressam condição quando o fato expresso por eles é uma condição necessária para que o evento da oração principal possa se realizar, enquanto expressam hipóteses, nos casos em que o fato expresso pela oração principal pode até ocorrer, sem que o fato por elas expresso necessariamente venha a acontecer. Acreditamos que os exemplos 8 e 12 ilustram bem o caso das hipotéticas e os exemplos 3 e 9 são bons dados para o caso das condicionais.

A segunda se refere ao fato de as gramáticas não tocarem na natureza silogística das condicionais, o que obrigaria a repor a discussão em outros termos: no fato de elas darem vida a eventos discursivos polifônicos ou heterogêneos. Para além das orações que se encontram relacionadas condicionalmente, há que se ouvir uma voz (o senso comum, a cultura, a ideologia) afirmando um princípio de validade geral, sobre o qual a relação $\mathrm{SE}>$ ENTÃo se articula. Considerese um dos exemplos: digamos o 13. Sustentando as orações que se ligam, deve-se ouvir uma voz que afirma que as viagens instruem, princípio que é negado pelo produtor do enunciado. Didaticamente, o silogismo se daria em termos de:

Premissa Maior: Os homens viajados são instruídos ou As viagens instruem os homens.

Premissa Menor: Os marinheiros viajam muito.

Conclusão: Os marinheiros são homens instruídos. 
Mas este raciocínio dedutivo é negado pelo autor, já que ele deve ter razões factuais para negar a premissa maior, que é silenciada, por ser culturalmente aceita. Mas deste aspecto tratamos adiante, quando nos dedicamos mais à questão das hipotéticas.

\section{Se, Então: O Ponto de Vista da Lingüística Textual}

A Lingüística Textual, diferentemente da Gramática Tradicional, que se pauta num recorte de estudo que coincide com, no máximo, a frase, enquanto extensão e num estudo que se pauta na abstração do objeto investigado, considera que os textos são a unidade elementar dos estudos de linguagem, motivada pela defesa de que certos fenômenos só podem ser explicados numa dimensão transfrástica, isto é, num nível de observação empírica que transcende a frase e considera o conjunto de enunciados componente do todo textual.

Embora os estudos de texto tenham evoluído e levado para o seu campo de preocupação elementos que, antes, eram ignorados (ingredientes como a situação sócio-comunicativa, os fatores pragmáticos, a intencionalidade e a intertextualidade, dentre outros), podendo-se até afirmar que, de certa forma, ela é uma das formas de análise do discurso, as tentativas iniciais de compreensão da atividade textual buscavam reduzi-lo aos recursos propriamente internos e estruturais de sua articulação, afirmando, às vezes, que o texto resultaria apenas da articulação de um conjunto de elementos lingüísticos organizados por uma macrossintaxe: uma cadeia pronominal ininterrupta.

Como qualquer outra teoria, assim que se torna pública e começa a ser tema de debates e pesquisas, tal limitação se torna incontornável e um conjunto de outros conceitos passa a ser incorporado para dar conta de explicar de que forma se tece a textualidade. Para Schmidt (1978, p. 164), é caracterizada por "uma dupla estrutura, isto é, uma estrutura a ser abordada tanto sob o ponto de vista lingüístico como sob o aspecto social". Aquilo que antes se pensava possível explicar de um ponto de vista lingüístico, imanente ou estrutural, incorpora elementos exteriores à estrutura para dar conta das demandas feitas em relação à teoria. Para Koch (1996), uma das 
brasileiras mais importantes desta corrente,

A Lingüística Textual toma, pois, como objeto particular de investigação não mais a palavra ou a frase isolada, mas o texto, considerado a unidade básica de manifestação da linguagem, visto que o homem se comunica por meio de textos $(\mathrm{KOCH}, 1996$, p. 14),

fazendo entrar no campo de estudos os protagonistas do ato comunicativo, que são exteriores ao texto, embora possam ser detectados em indícios lingüísticos. E é justamente sobre os procedimentos de conectividade lingüística que a Lingüística Textual construirá um dos seus domínios de estudo: sobre os, assim chamados, elos coesivos: ei-nos de volta aos recursos conectores condicionais.

Para esta disciplina, assim como para a Gramática Tradicional, os conjuntivos do tipo condicional também articulam enunciados entre si, sendo que aquele introduzido pela conjunção de condicionalidade expressa a condição ou hipótese para que o outro se realize, assim como ela o considera um conector lógico-semântico. Para Koch (1996, p. 62), uma relação de condicionalidade se expressa "pela conexão de duas orações" e "o que se afirma nesse tipo de relação é que, sendo o antecedente verdadeiro, o conseqüente também o será". A autora dá como exemplos os enunciados

14) [Se aquecermos o ferro, $]_{1}$ [ele se derreterá. $]_{2} \mathrm{e}$

15) $[\text { Se fizer sol, }]_{3}$ [então iremos à praia. $]_{4}$,

entendendo que entre 1 e 2 e 3 e 4 se estabelecem relações lógicas (se o antecedente é verdadeiro, o conseqüente também é) e que 1 e 3 expressam as condições ou hipóteses que devem ser atendidas para que 2 e 4 possam se realizar.

A autora (1987, p. 126) afirma que as "condicionais são proposições formadas por duas partes ligadas pela conjunção se, em que a primeira, que encerra a condição, constitui o antecedente e a segunda, o conseqüente", mantendo-se fiel, em 1996, ao princípio estabelecido quase uma década antes. Naquele momento, ela apresentava como exemplos para as relações condicionais os enunciados 
16) [Se a alma é espiritual, $]_{1}$ [ela é imortal. $]_{2} \mathrm{e}$

17) [Se Deus é justo, $]_{3}$ [os maus serão punidos. $]_{4}$,

permitindo inferir que, entre 1 e 2 e 3 e 4, existe uma relação lógica e que 1 e 3 expressam as condições ou hipóteses para que a verdade de 2 e 4 possam ser afirmadas.

Não é preciso acrescentar outros dados ao rol de ilustrações se o objetivo é mostrar como a Lingüística Textual encara os conetivos condicionais e como os seus postulados são próximos, se não são coincidentes, com os da Gramática Tradicional. Porém é justamente este quadro aparentemente bem assentado e relativamente acordado que pretendemos discutir. Pensamos que, às vezes, nos acostumamos a assumir rápido demais afirmações que, por serem bastante enfatizadas, acabam criando um efeito de naturalização.

\section{Buscando Problematizar um Pouco o Quadro}

Não negamos que entre os enunciados ligados pelo se (e seus correlatos) exista uma relação de condicionalidade e nem que ela seja tomada, em geral, como tendo uma natureza lógico-semântica, afirmação que, de certa forma, somos obrigados a admitir, já que a relação semântica se estabelece também a partir da inter-relação que se opera entre as duas porções do enunciado ligadas pelo conetivo em estudo. Também devemos admitir que os conectores, de forma geral, operam elos transfrásticos, havendo um desequilíbrio entre o tratamento dado para eles pela Gramática Tradicional e pela Lingüística Textual, pois, para a primeira, eles agem no interior de um mesmo período e, para a segunda, os níveis de articulação perpassam o texto como um todo, tomando como parâmetro de conexão a estrutura macrossintática do texto. Mas julgamos pertinente levantar algumas questões que ficam em silêncio; outras que restam mal resolvidas; e, por fim, outras que parecem criar uma contradição interna à teoria.

Dentre as questões que ficam em silêncio, uma delas se refere ao fato de que não se busca explicar como se constitui e como se sustenta a relação condicional que se afirma existir entre as orações unidas pelo se; ou seja, em que se amparam os enunciados ligados de forma condicional para criar tal forma de relação? Por que razão, se o antecedente não se realiza, o conseqüente também não ocorre? De 
onde vem o princípio normativo ou determinativo (estes termos não são sinônimos) que faz com que a relação entre os enunciados seja condicional, embora nem sempre do tipo condição sine qua non?

Dentre as questões mal resolvidas, a que fica mais saliente é relativa ao fato de não se buscar esclarecer qual a diferença entre relações condicionais e hipotéticas, já que elas não se reportam ao mesmo princípio discursivo e permitem, inclusive, fazer a hipótese de que, num caso, o ancoradouro é um e, no outro, é outro. Julgamos poder fazer a hipótese de que, no caso das condicionais, a relação se faz no plano da necessidade, enquanto que, no caso das hipotéticas, o requisito solicitado não é obrigatório, devendo haver uma razão para isso. Destes dois conjuntos de questões tratamos adiante, quando buscamos recolocar as condicionais sob outro enfoque de análise.

E, por fim, dentre as que geram uma contradição epistemológica, uma se refere ao fato de a Lingüística Textual pleitear como pressupostos o fato de que a linguagem seria interativa, de que o recorte de estudos seria o texto, já que seria por meio dele que os homens interagiriam, e que o mesmo teria um caráter essencialmente argumentativo, parecendo ficar contraditório criar uma dicotomia entre conetivos lógico-semânticos e operadores discursivo-argumentativos. Como pensar em relações puramente lógicas ou substancialmente semânticas, quando o texto seria um fenômeno essencialmente interativo. Todos os conectores não seriam, deste ponto de vista, discursivamente argumentativos?

Considerando as afirmações de Koch $(1987$, p. 17) de que "a linguagem passa a ser encarada como forma de ação, ação sobre o mundo dotada de intencionalidade, veiculadora de ideologia, caracterizando-se, portanto, pela argumentatividade", de que "A interação social, por intermédio da língua, caracteriza-se, fundamentalmente, pela argumentatividade" (KOCH, 1987, p. 19) e de que "a argumentação constitui atividade estruturante de todo e qualquer discurso" (KOCH, 1987 , p. 23), pensamos ser inviável pleitear que certos conectores meramente articulam "uma relação entre o conteúdo de duas orações" (KOCH, 1996, p. 65), enquanto outros, "ao introduzirem um enunciado, determinam-lhe a orientação argumentativa". Julgamos que se deva radicalizar a concepção interacionista de linguagem, tomando cada ingrediente lingüístico utilizado como materializador de uma opção discursiva, considerando-se as condiçãoes de produção em que o 
mesmo passou a ser um constituinte textual. Consideramos, pois, doravante, que os conetivos condicionais são operadores discursivos, mas que se devem distinguir dois tipos entre eles.

\section{Transversalidade e Lastro Cultural}

Buscamos, a seguir, delinear um conceito relevante para este estudo: o de transversalidade discursiva. Falar de discurso obriga o analista a levar em consideração pelos menos duas ordens de problemas: os protagonistas do ato comunicativo, com tudo que decorre de sua inserção, devem ser considerados no momento de precisar o efeito de sentido de um texto, caracterizado por uma incompletude fundante; por isso, a relação existente entre o texto (o plano da expressão e do conteúdo) e o contexto (em sentido lato: a situação comunicativa; em sentido estrito: as condições de produção) deve ser vista como constitutiva, não se podendo lidar de maneira efetiva com o sentido, a não ser por meio da consideração da dupla face do discurso, simultaneamente, lingüístico e histórico.

Esse caminho de mão dupla tecido entre o texto e o contexto permite, por um lado, desvendar as razões de a materialidade discursiva ter sido produzida de uma forma e não outra e, por outro, alcançar o lastro cultural que sustenta os enunciados realizados pelo enunciador: ou seja, se a materialidade discursiva é tomada em consideração, ela dá acesso à formatação imposta sobre o mundo, ao mesmo tempo em que permite o acesso às razões sociais de tal forma de compreensão. Considerar o texto como discurso permite que se vejam que formas de concepção de mundo são construídas, quais as razões de elas serem essas e não outras, que segmento social as produz e o que ele ganha com isso.

Com relação ao conceito de transversalidade, um exemplo pode ajudar a precisar o efeito de sentido que pretendemos para ele. Numa eleição municipal, uma candidata a vereadora dizia em sua propaganda: "Sou candidata a vereadora, sou mulher, mas pretendo fazer um bom trabalho". Nada (e tudo) a recriminar. Numa conversa em que perguntava o que achava de as mulheres participarem da vida política, ela afirmava que as mesmas reúnem as condições necessárias para fazerem parte da administração pública das cidades. Contradição? 
Incoerência? O que a teria levado ao uso do mas, causador do "problema"?

Tudo a recriminar, pois a candidata diz que quer ser vereadora (o que não é preciso, já que ela falava num programa destinado a apresentar os candidatos a vereadores, mas esse é apenas um pequeno deslize pragmático), que é mulher (o que não é necessário, já que a sua voz identificava o seu gênero, mas esse também é apenas mais um deslize pragmático) e que pretende fazer um bom trabalho, o que não deixa de ser elogiável (talvez ela também não devesse dizer isso, já que se pressupõe que candidatos à vida pública devam buscar fazer um bom trabalho: é para isso que são pagos): mas também, se isso não deveria ser dito, porque era irrelevante, o que deveria ser dito então? Situação problemática.

No entanto, nada a recriminar. Por quê? É evidente que a candidata sabe que o seu interlocutor sabe que ela é candidata a vereadora, que é mulher e que, em tese, deverá buscar atender à exigência de fazer um bom trabalho. Então, para que dizer o que diz? Se sabe que o seu interlocutor conhece as informações que está dando, por que, mesmo assim, as explicita? É aqui que o conceito de transversalidade pode ser demonstrado.

Se, pragmaticamente, pode ser recriminada, já que transgride a lei conversacional da relevância, preenchendo lacunas que seu interlocutor faria por si mesmo, discursivamente, o enunciado é bem comportado (ambiguamente). Bem comportado, antes, porque não rompe com o imaginário do grupo social que sancionou os saberes de que os políticos nem sempre têm feito um bom trabalho (havendo, pois, a necessidade de o candidato se comprometer com isso) e que mulheres, geralmente, são tidas como incompetentes para a administração pública (crença que o enunciado ratifica, mas visa a apresentar a candidata como uma exceção). Ironicamente, a candidata se elegeu e a maioria dos seus votos foi de mulheres.

Uma maneira de o enunciado ser analisado pode ser a que segue: a) a candidata julga que deve dizer que pretende ser vereadora; b) ao dizer que é candidata, ela possui um saber que diz que a sociedade não vê com bons olhos candidatos a cargos públicos; c) então, ela conclui que sua pretensão será passível de crítica; d) dizendo que pretende fazer um bom trabalho, por um lado, ela ratifica o senso 
comum e a crença social existente e, por outro, com o uso do mas, ela nega que o princípio seja aplicável a ela; e) a candidata julga que deve dizer que é mulher; f) ao afirmar isso, ela possui um saber que diz que a sociedade pensa que mulher não é competente para ocupar cargos públicos; g) ela conclui, então, que sua pretensão será passível de crítica; h) dizendo que pretende fazer um bom trabalho, por um lado, ela ratifica a crença social sobre a mulher e, por outro, com o uso do mas, ela nega que o princípio lhe seja imputável. Polivalente, o mas desempenha um papel múltiplo: a) contradiz a conclusão lógica que se poderia tirar da primeira parte do enunciado: "sou candidata a vereadora"; b) nega a conclusão lógica que se poderia inferir da segunda parte do enunciado: "sou mulher"; c) ratifica as crenças existentes sobre os políticos e a mulher na administração pública; d) nega que essas crenças sejam aplicáveis à candidata específica que pretende ser vereadora. Talvez se pudesse recriminar a candidata por ratificar o senso comum existente, mas, como afirma Bourdieu (1999), esse conjunto de pressupostos imperativos "se alicerça num inconsciente ao mesmo tempo coletivo e individual, traço incorporado de uma história coletiva e de uma história individual que (se) impõe a todos os agentes, homens ou mulheres", os quais raramente apercebem-se das crenças que comandam seus discursos.

Onde situar, na análise efetuada, o conceito de transversalidade? Pode-se perceber que só se chega a saber que os políticos em geral e as mulheres candidatas a cargos públicos são representados de forma negativa, quando se cruzam a parte $a$ do enunciado (sou candidata a vereadora) e a parte $b$ (sou mulher) com a parte $c$ (mas pretendo fazer um bom trabalho). O pano de fundo que sustenta os discursos não é explicitado: ele é tomado como sabido, como dominado pelos interlocutores. É isso que permite que os textos não tenham que dizer tudo explicitamente, deixando em suspenso informações que são de domínio comum. Por outro lado, a via de acesso para esse lastro cultural que sustenta os discursos é possibilitado pelo cruzamento de partes do enunciado, como se fez acima entre as partes $a$ e $b$ com a $c$. É a essa atividade de cruzamento entre as partes de um enunciado que chamamos de tranversalidade do discurso. Não são as partes explícitas que levam a recriminar o comportamento da candidata, mas o cruzamento das suas afirmações, pois a atividade leva "ao sistema de pressupostos 
imperativos" do que ela diz. Chamamos de pano de fundo o sistema de pressupostos; e chamamos de transversalidade o cruzamento de partes do enunciado para obter os implícitos do discurso.

\section{O Caso das Condicionais e Hipotéticas}

Enfim, passamos a nos dedicar exclusivamente ao tema proposto para este estudo: o caso dos conetivos condicionais. Em que eles se baseiam, qual o alicerce que os sustenta e em que se funda a diferença hipotética e condicional pleiteada entre eles. Partimos da crença de que os conetivos condicionais estabelecem uma relação condicional ou hipotética entre os enunciados que ligam e a damos como aceita incondicionalmente. Chamamos a atenção inicialmente para alguns aspectos importantes e, em seguida, me dedico ao tipo de condicional que julgamos importante situar na discussão, destinando-lhe um lugar específico.

De início, consideramos que, assumindo-se o ponto de vista de que a linguagem é uma forma de interação, se corre o risco de criar um desequilíbrio interno à teoria, se for assumido, de um lado, que há conetivos lógico-semânticos e, de outro, que há operadores discursivo-argumentativos. Embora admitamos que, no caso dos primeiros, há uma relação de implicação entre as orações ligadas (do tipo causa e efeito, antecedente e conseqüente, ou outra qualquer), tais relações semânticas também existem entre os enunciados ligados pelos segundos, mesmo que se possa dizer que eles têm alguma nuança diferencial na forma do encadeamento que estabelecem. Entendemos que qualquer conetivo conjuntivo que relaciona enunciados entre si objetiva, por meio do conjunto resultante, alcançar efeitos argumentativos e discursivos frente ao interlocutor. Esta é a razão de os enunciados complexos serem produzidos. Não se produz uma relação articulada condicionalmente, que não seja para persuadir ou convencer alguém de alguma coisa: a não ser para, conforme Koch (1987, p. 17),

estabelecer com ele relações dos mais variados tipos, de obter dele reações ou comportamentos, de atuar sobre ele das mais diversas maneiras, enfim, de interagir socialmente por meio do seu discurso. 
Acreditamos que, na verdade, qualquer elemento conjuntivo tem fins argumentativos: relações semânticas por relações semânticas, todos eles produzem, mas o objetivo maior não está nesta criação. A distinção entre conetivos lógicos e operadores argumentativos não chega a recolocar devidamente em outro quadro a perspectiva gramaticalista, gerando um aparente desequilíbrio numa teoria que fica a meio caminho neste aspecto da sua sistematização.

Em segundo lugar, e como já adiantamos, acreditamos possível defender que existam dois se(s) e busco diferenciá-los melhor a seguir. Por ora, gostaríamos de, valendo-nos da noção de transversalidade discursiva tecida acima, demonstrar a natureza heterogênea e polifônica de ambos, buscando elucidar as diferentes origens da constituição de ambos por múltiplas vozes. Tomamos, para demonstração, os dois exemplos a seguir (18 e 19), considerando-os, respectivamente, como criadores de relações hipotéticas e condicionais.

18) [Se ela viesse mais à igreja, $]_{1}$ [haveria de ser uma santa. $]_{2}$

Para a demonstração da constituição polifônica do enunciado, pode-se buscar detectar e explicitar sobre que princípio de crença (e não de conhecimento) ele se fundamenta, o que poderia ser descrito como segue:

Premissa maior: A ida à igreja torna as pessoas santas.

Premissa menor: Ela vai pouco à igreja.

Conclusão: Ela não chegará a ser santa.

Embora busque aparentar uma relação de condicionalidade necessária entre as orações 1 e 2 , não se pode afirmar que a conseqüência apontada deva obrigatoriamente ocorrer se o antecedente for atendido: nem todos os que vão assiduamente à igreja se tornam santos e nem todos que, renitentemente, deixam de ir estarão impedidos de serem considerados portadores dessa característica. Exemplos não faltam, dados pela própria igreja, que não beatifica ou santifica todos os seus freqüentadores assíduos, assim como não deixa de considerar como santas pessoas que não foram exatamente modelares no que se refere à freqüência aos rituais religiosos. O máximo 
que se pode dizer do exemplo 18 é que ele se constitui num raciocínio hipotético, que poderia ser parafraseado ou ampliado por na hipótese de ela vir mais à igreja, talvez ela pudesse vir a ser mais santa, fato ou evento que ninguém em sã consciência se prontificaria a afirmar como resultado positivo ou categórico.

Dois episódios discursivos que poderiam suceder a enunciação de 18 nos parecem permitir afirmar que o raciocínio feito nele é apenas hipotético e não condicional. Atendidas certas condições, o enunciado poderia ser submetido a uma enunciação irônica que comportasse um ingrediente de negação e descrença. Suponhamos, por exemplo, que um padre tivesse dito sobre uma mulher que, se ela fosse mais à igreja, viria a ser santa e que tal atitude por parte dela passasse a ocorrer. Decorrido certo tempo, talvez ela até se tornasse mais santa, mas não há como garantir que isso aconteceria. Permanecendo a mesma ou até mesmo cometendo algum pecadilho, alguém que tivesse ouvido o enunciado do padre poderia repeti-lo num tom jocoso, questionando o enunciador sobre a validade do princípio em que se baseava. Temos a impressão, portanto, de que o fundamento discursivo de 18 não é um princípio absolutamente verdadeiro, mas apenas circunstancial, podendo ser validado em alguns casos; em outros, não. E acreditamos, por outro lado, que nem todos os enunciados ligados por conetivos condicionais admitem esta contraenunciação irônica. Da mesma forma, atendidas certas condições, o enunciado proferido em 18 poderia ser contradito por um enunciado que se encadeasse sobre ele, valendo-se de um conetivo adversativo, ou, para a Lingüística Textual, de uma contrajunção, também invalidando o efeito de sentido sobre o qual as orações relacionadas estão ancoradas. $\mathrm{Na}$ mesma situação descrita acima, alguém poderia dizer: "ela veio à igreja, mas não se tornou santa; aliás, permanece a mesma" (ou: "aliás, se tornou menos atenciosa com as pessoas"). Julgamos que a possibilidade de receber como comentários encadeados ou um enunciado irônico ou um enunciado contrajuntivo sejam dois mecanismos relativamente seguros de definir quando um raciocínio transversalmente se ancora numa hipótese ou numa condição. 
19) $[\text { Se aquecermos o ferro, }]_{1}$ [ele se derreterá. $]_{2}$

Para explicitar a heterogeneidade de vozes sobre a qual se articula o enunciado, basta que, como antes, se procure trazer à tona a sua constituição silogística e se possa perceber, então, o princípio de conhecimento (e não de crença) que o sustenta, princípio este ancorado numa voz que o antecede mas que, desta vez, remete a um outro sistema de referência.

Premissa maior: Quando o ferro é aquecido, ele se derrete.

Premissa menor: Se o ferro for aquecido,

Conclusão: ele se derreterá.

É óbvio que se tem que ressaltar que não é a qualquer grau de temperatura que o ferro derrete. Alguém poderia dizer que aqueceu uma peça de ferro e ela não derreteu, mas o locutor sempre poderia lhe dizer que ele não submeteu o metal à temperatura adequada, o que manteria o princípio de fundo, ainda assim, válido. Isto não ocorre em 18, pois a mulher poderia se tornar mais santa não indo à igreja e menos santa freqüentando-a. Acreditamos que apenas em 19 se possa dizer que entre as partes 1 e 2 do enunciado haja um raciocínio condicional, já que é necessariamente verdadeiro que o ferro aquecido, à temperatura adequada, sempre derrete. É difícil imaginar um enunciado como 19 ser objeto de uma contra-enunciação irônica ou contrajuntiva. Isto até pode acontecer, mas o produtor do enunciado poderá mostrar que tem razão e que seu interlocutor não agiu adequadamente para obter o efeito ou resultado esperado. Pensamos que, na base de raciocínios como os feitos em 19, esteja um princípio de necessidade, de inegabilidade, de infalibilidade: podem até variar as condições para se obter a conseqüência, mas ela ocorrerá, de uma forma ou de outra. Já em 18, o princípio está calcado num caráter de possibilidade, de probabilidade e de falibilidade. É claro que sempre se pode afirmar que ambos tomam o mundo objetivo como parâmetro, mas talvez seja necessário admitir que, num caso, a teoria se conforma aos dados, enquanto no outro, os dados devem se conformar à teoria: aqui, estamos no mundo da cultura e das crenças, no terreno da profecia que, conforme afirma Bourdieu (1998), se auto-realiza. 
Designamos, doravante, os conetivos do tipo condicional de $\boldsymbol{s e}_{2}$ e os do tipo hipotético de $\boldsymbol{s e}_{1}$, por acreditar, embora ainda não tenhamos parâmetro empírico para afirmar isso, que estes ocorrem em maior número, são muito mais eficazes do ponto de vista cultural e ajudam a cumprir extremamente bem o papel de manutenção do status quo. Acreditamos que os primeiros sejam determinativos, enquanto os segundos sejam normativos. E, como afirma Gadamer (1997), frente à necessidade, só cabe a aceitação; frente à possibilidade, cabem a discussão, a reflexão e a interpretação: outra forma de leitura de mundo.

Dedicamo-nos, para concluir, aos condicionais hipotéticos (denominação que, à luz do que foi discutido, agora, soa como um paradoxo), já que, dentre os dois, apenas eles acessam o mundo das crenças e ao "sistema de pressupostos imperativos" (BOURDIEU, 1999, p. 70) de uma prática cultural, lugar ímpar, quando se trata de ver como a linguagem materializa uma visão de mundo. Tomamos como fio de reflexão a idéia de "anamnese cultural" (BOURDIEU, 1999, p. 70), que se refere não à "aquisição de um simples saber, mas à que advém da reapropriação de um conhecimento, ao mesmo tempo possuído e perdido desde sempre" e a afirmação de Barthes (1990, p. 24) de que "a análise dos códigos talvez permita definir historicamente uma sociedade mais facilmente e com mais segurança do que a análise de seus significados".

\section{Exemplo número 1}

$[\text { Se você se esforçasse mais, }]_{1}$ [teria vencido como eu. $]_{2}$

Este enunciado foi proferido pelo dono de uma revendedora de carros, sujeito bem sucedido financeiramente e pertencente à alta sociedade de uma cidade qualquer, para o seu irmão que, tendo feito a opção pela agricultura, no momento em que esta interação acontecia, passava por dificuldades financeiras. A conclusão óbvia a que o enunciado conduz (eis a razão para defendermos que todos os enunciados constituem eventos argumentativos, mesmo que isto seja feito em conjunto pelas partes 1 e 2 do enunciado) é que o interlocutor não venceu na vida e está passando por dificuldades por ter se esforçado pouco e, para qualquer um que conheça, mesmo que superficialmente, a vida agrícola, sabe que ela não é uma atividade que 
exige pouco esforço de quem a pratica. De onde vem a lógica que ampara o raciocínio implicativo? Em que ela está amparada? Qual é a voz que, polifonicamente, cruza transversalmente o enunciado? Para percebê-la, deve-se decompor o plano explícito do enunciado, buscando desnudar a sua constituição silogística. Ei-la:

Premissa maior: Quem se esforça vence na vida.

Premissa menor: O locutor se esforçou muito.

Conclusão: Ele venceu na vida.

Premissa menor: O outro não se esforçou como o locutor.

Conclusão: Ele não venceu na vida.

Mescla de raciocínio hipotético (se eu me esforçasse, se você se esforçasse), adversativo e comparativo (mas você não se esforçou, como eu me esforcei) e conclusivo (portanto eu venci, portanto você não venceu), apenas se alcança o que alicerça o discurso na medida em que se explicita qual é a voz que, polifonicamente, o sustém: se esta é a voz da ideologia, do imaginário social, da mentalidade cultural ou do inconsciente coletivo, não cabe tomar partido agora. Deve-se perceber, porém, que o raciocínio camuflado condicionalmente, nada mais é do que uma relação de implicação hipotética, pois não faltam casos de quem pouco se esforça e vence na vida e de quem se esforça muito e não chega a constituir uma vida farta. Acreditamos que, por detrás da máscara da condicionalidade, a relação se limite a ser uma possibilidade amparada numa crença cultural, que não é única, nem pode ter a pretensão de se impor a todos como grade de leitura. Julgamos que o enunciado acima suportaria uma contra-enunciação irônica ou adversativa, o que demonstra que a sua natureza é hipotética e não condicional. É a isso que anteriormente chamamos de princípio normativo (norma social, cultural ou ideológica) e não determinativo, pois a implicação ocorre como uma possibilidade e não como uma necessidade: para sermos mais precisos, ela se dá no terreno da cultura. Eis a necessidade de os estudos da linguagem aprenderem a se perguntar "por que se diz aquilo que se diz do jeito que se diz".

Para não correr o risco de nos tornarmos enfadonhos, limitamo-nos a apresentar mais dois exemplos e a decompô-los 
sumariamente. Temos a certeza de que o leitor saberá executar o resto do percurso. Ademais, há todos os exemplos retirados de gramáticas e citados anteriormente que podem ser utilizados.

\section{Exemplo número 2}

[Se eu tivesse estudado, $]_{1}$ [estaria bem hoje. $]_{2}$

Premissa maior: Quem estuda vence na vida.

Premissa menor: Você estudou.

Conclusão: Hoje, você está bem.

Premissa menor: Eu não estudei.

Conclusão: Eu não estou bem.

\section{Exemplo número 3}

[Se você fosse à igreja, $]_{1}$ [não teria problemas no trabalho. $]_{2}$

Premissa maior: A ida à igreja evita problemas no trabalho.

Premissa menor: Você não vai muito à igreja.

Conclusão: Você tem problemas no trabalho.

Basta que o leitor saiba que o exemplo de número 2 foi produzido pelo pai de um dos autores deste texto, num momento em que discutiam a situação atual dos brasileiros e dos membros da família, e que o exemplo de número 3 foi proferido pela mãe, quando, de certa forma, ele reclamava do estresse no trabalho. Não é necessariamente verdadeiro que quem tenha estudado esteja bem de vida atualmente e que quem não o tenha feito esteja passando necessidades, nem é obrigatoriamente correto que quem vá à igreja não enfrente problemas do trabalho e quem não vá possa não enfrentar dificuldades. Em que se amparam as suas "lógicas"? Elas são resquícios de um saber "ao mesmo tempo possuído e perdido desde sempre", mistura de crenças, mitos, ideologias, jargões e clichês que lograram adquirir efeitos de naturalização (é assim, porque sempre foi assim), antigos textos terna e eternamente repetidos, lembranças que se tem e não se sabe ter: isto tudo vem tomar corpo e forma na linguagem que se usa, ou melhor, na língua, a sua expressão. Como diz Barthes (1990, p. 14), ela "não é reacionária, nem progressista; ela é simplesmente: fascista, pois o fascismo não é impedir de dizer, é obrigar a dizer". 
Cabe, de acordo com o autor, superar a autoridade da asserção e do gregarismo que nela se delineiam, por meio do seu desmonte e a trapaça com o plano do significante, aligeirando o poder que nele se institui. Que isto comece, transite ou termine no estudo de como os conetivos lingüísticos funcionam é uma questão de escolha do estudioso: uma escolha que precisa ser feita, se ele quiser compreender a cultura e por que pensamos o que pensamos.

\section{Referências Bibliográficas}

ALMEIDA, Napoleão Mendes. Gramática metódica da língua portuguesa. 28. ed. São Paulo: Saraiva, 1979.

ANDRÉ, Hildebrando de. Gramática ilustrada. 2. ed. São Paulo: Moderna, 1978.

BARTHES, Roland. Aula. Trad. Leyla Perrone-Moisés. 6. ed. São Paulo: Cultrix, 2000.

O óbvio e o obtuso: ensaios sobre fotografia, cinema, pintura, teatro e música. Trad. Léa Novaes. Rio de Janeiro: Nova Fronteira, 1990.

BECHARA, Evanildo. Moderna gramática portuguesa. 37. ed. Rio de Janeiro: Lucerna, 2003.

BOURDIEU, Pierre. A dominação masculina. Trad. Maria Helena Kühner. Rio de Janeiro: Bertrand Brasil, 1999.

A economia das trocas lingüísticas: o que falar quer dizer. Trad. Sergio Miceli et. al. 2. ed. São Paulo: Edusp, 1998.

CEGALLA, Domingos Paschoal. Novíssima gramática da língua portuguesa. 22. ed. São Paulo: Companhia Editora Nacional, 1981.

CUNHA, Celso; CINTRA, Lindley. Nova gramática do português contemporâneo. 2. ed. 38. reimp. Rio de Janeiro: Nova Fronteira, 1999. 
FARACO, Carlos Emílio; MOURA, Francisco Marto de. Gramática. 10. ed. São Paulo: Ática, 1997.

GADAMER, Hanz-Gerg. Verdade e método: traços fundamentais de uma hermenêutica filosófica. 2. ed. Petrópolis: Vozes, 1997.

$\mathrm{KOCH}$, Ingedore Villaça. O texto e a construção dos sentidos. São Paulo: Contexto, 1998.

A coesão textual. São Paulo: Contexto, 1996.

A inter-ação pela linguagem. São Paulo: Contexto, 1992.

A coerência textual. São Paulo: Contexto, 1990.

. Argumentação e linguagem. 2. ed. São Paulo: Cortez, 1987.

LIMA, Rocha. Gramática normativa da língua portuguesa. 26. ed. Rio de Janeiro: José Olympio, 1985.

SCHMIDT, Siegfried J. Lingüística e teoria de texto. Trad. Ernst F. Schurmann. São Paulo: Pioneira, 1978. 